\title{
Damage accumulation during cyclic loading of a continuous alumina fibre reinforced aluminium composite
}

\author{
B. Moser ${ }^{\mathrm{a}, \mathrm{b}, *}$, L. Weber $^{\mathrm{a}}$, A. Mortensen ${ }^{\mathrm{a}}$ \\ a Ecole Polytechnique Fédérale de Lausanne (EPFL), Laboratory for Mechanical Metallurgy, Lausanne, Switzerland \\ ${ }^{\mathrm{b}}$ Laboratory for Materials Technology Thun, Empa Materials Science and Technology, Thun, Switzerland
}

Received 19 July 2005; accepted 25 July 2005

Available online 22 August 2005

\begin{abstract}
Fibres fracture gradually during the fatigue cycling of continuous alumina fibre reinforced aluminium. The number of fibre breaks increases linearly with the logarithmic cycle number, depends on the maximum stress and the stress ratio, and agrees with published data for the fatigue of bare fibres.
\end{abstract}

(C) 2005 Acta Materialia Inc. Published by Elsevier Ltd. All rights reserved.

Keywords: Aluminium; Fatigue; Fracture; Fibers; Metal matrix composites MMC

\section{Introduction}

The fatigue performance of fibre reinforced metals has been extensively investigated, with prime focus on $\mathrm{SiC}$ monofilament reinforced Ti-matrix composites $[1,2]$. Fatigue mechanisms and properties in this system are now reasonably well understood and documented [1,3-7]. Other systems that have been characterized in fatigue include composites of aluminium reinforced with glass [8], $\mathrm{SiC}$ [9], B [10], or first-generation alumina fibres [10-13]. Comparatively, the newer generation of high-performance Nextel $610^{\mathrm{TM}}$ alumina fibre reinforced aluminium composites $[14,15]$ have, from this standpoint, only received limited attention [16-18].

Matrix cracking, interfacial debonding, or a combination of both are the main internal damage mecha-

\footnotetext{
${ }^{*}$ Corresponding author. Address: Laboratory for Materials Technology Thun, Empa Materials Science and Technology, Thun, Switzerland.

E-mail address: benedikt.moser@alumni.ethz.ch (B. Moser).
}

nisms that have been found during fatigue of fibre reinforced metals $[1,2]$. In a recent study of the tensile properties of virgin Nextel $610^{\mathrm{TM}}$ fibres, it was found that cyclic loading causes failure of the fibres at stresses noticeably lower than the average tensile fibre strength in monotonic loading [19].

This finding suggests that, in composites reinforced with such fibres, damage accumulation may also proceed by progressive degradation of the intrinsic fibre strength. Using a newly developed technique for the measurement of internal damage in fibre reinforced aluminium, we report here that such degradation does indeed occur in composites of pure aluminium reinforced with Nextel $610^{\mathrm{TM}}$ alumina fibres.

\section{Materials and experiments}

\subsection{Material}

The composite investigated is a continuous wire of 99.98\% pure aluminium reinforced with high-strength continuous $\alpha$-alumina fibres and supplied on a reel. 
Table 1

Main properties of the Nextel 610 alumina fibre

\begin{tabular}{ll}
\hline Composition [20] & $>99 \alpha-\mathrm{Al}_{2} \mathrm{O}_{3}$ \\
& $0.2-0.3 \% \mathrm{SiO}_{2}$ \\
Mean UTS at $L_{0}=25.4 \mathrm{~mm}[15,21]$ & $0.4-0.7 \% \mathrm{Fe}_{2} \mathrm{O}_{3}$ \\
Weibull modulus [15] & $3.3-3.47 \mathrm{GPa}$ \\
Young's modulus [15] & $9.7-11.2$ \\
Density $[15,20]$ & $373 \mathrm{GPa}$ \\
Diameter $[15]$ & $3.75-3.9 \mathrm{~g} \mathrm{~cm}^{-3}$ \\
$\mathrm{CTE}\left(100-1100^{\circ} \mathrm{C}\right)[27]$ & $11.98 \mu \mathrm{m}$ \\
\hline
\end{tabular}

The reinforcement of the wire consists in about 50 vol.\% of the continuous alumina fibre Nextel $610^{\mathrm{TM}}(3 \mathrm{M}, \mathrm{St}$ Paul, MN, USA). Principal properties of this highperformance ceramic fibre are summarized in Table 1; more data can be found in Refs. [15,20,21]. The final wire has a roughly circular cross-section with an equivalent diameter of $1.99 \mathrm{~mm}$ (determined by volume measurement).

\subsection{Fatigue testing and damage measurement}

The wire was subjected to cyclic loading using a Zwick010 (Zwick, Ulm, Germany) screw-driven universal testing machine with computer control and equipped with a $10 \mathrm{kN}$ load cell. The wire was glued at each end into a carbon steel tube with $3 \mathrm{~mm}$ inner diameter and gripped by mechanical grips on the steel tube. Two different $R$-ratio $\left(R=\frac{\sigma_{\min }}{\sigma_{\max }}\right)$ values, $0.1-0.9$ and three different maximum loads (corresponding to peak stresses of 1100,1160 and $1220 \mathrm{MPa}$ ) were applied. The tests were performed in displacement control with a triangular waveform and constant load amplitude enforced with a frequency of roughly $0.15 \mathrm{~Hz}$. The specimens were cycled to varying numbers of cycles, mostly without failure, and then removed from the machine for damage measurement. Some specimens failed during cycling, thus yielding a few measures of the fatigue life of the wire.

Fibre damage in the wire, before and after cyclic loading, was measured using a method recently developed by the authors [22]. In brief, tensile tests were conducted on the wire while a selected length, $l$, of the wire was heated to $775^{\circ} \mathrm{C}$ to melt the matrix. These tests were performed using the same screw-driven universal testing machine as used for the fatigue cycles. In order to introduce the fatigued specimen into the furnace, one end of the wire was cut right at the steel tube and then gripped directly with mechanical grips. The tests were conducted under a constant crosshead displacement speed of $0.2 \mathrm{~mm} / \mathrm{s}$, corresponding to a nominal strain-rate of roughly $9 \times 10^{-4} \mathrm{~s}^{-1}$. The maximum stress is calculated from the maximum load divided by the average initial wire cross-section area before melting.

\section{Results}

\subsection{Fatigue life of failed samples}

Samples that were cycled to failure were ones that broke before the end of the test as it was planned. As a consequence, stress and cycle number of these specimens are not statistically representative cyclic strength data (since these samples were at the lower end of the strength distribution among the present samples). Among these, one broke after 5047 cycles with a peak stress of $1100 \mathrm{MPa}$; one broke after 7650 cycles and another after 1216 cycles with a peak stress of 1160 $\mathrm{MPa}$ while five samples broke with a peak stress of $1220 \mathrm{MPa}$, after 2, 3, 15, 30, and 57 cycles, respectively. All these samples were tested with $R=0.1$.

\subsection{Internal damage}

A virgin wire tested at $775^{\circ} \mathrm{C}$ with a molten section of length $l=230 \mathrm{~mm}$ has an average strength $\sigma_{\text {molten }}^{\text {virgin }}$ $446 \mathrm{MPa}$. This value is different from what was found in Ref. [22]; this is a result of spool to spool variations in the level of internal damage [23].

Fig. 1 plots the fracture stress $\sigma_{\text {molten }}$ of the same composite wire, again with a molten zone of length $l=230 \mathrm{~mm}$, as a function of the number of fatigue cycles $N$ applied beforehand at room temperature with $R=0.1$, for three values of the peak stress, $\sigma_{\max }$, namely 1100,1160 and $1220 \mathrm{MPa}$. As seen, $\sigma_{\text {molten }}$ decreases in a log-linear manner with increasing $N$. Increasing the peak stress results in a lower absolute value of $\sigma_{\text {molten }}$ and in a greater rate of wire strength degradation during cycling.

Fig. 2 shows the influence of the cycling stress ratio, $R$, on the measured residual fracture strength of the

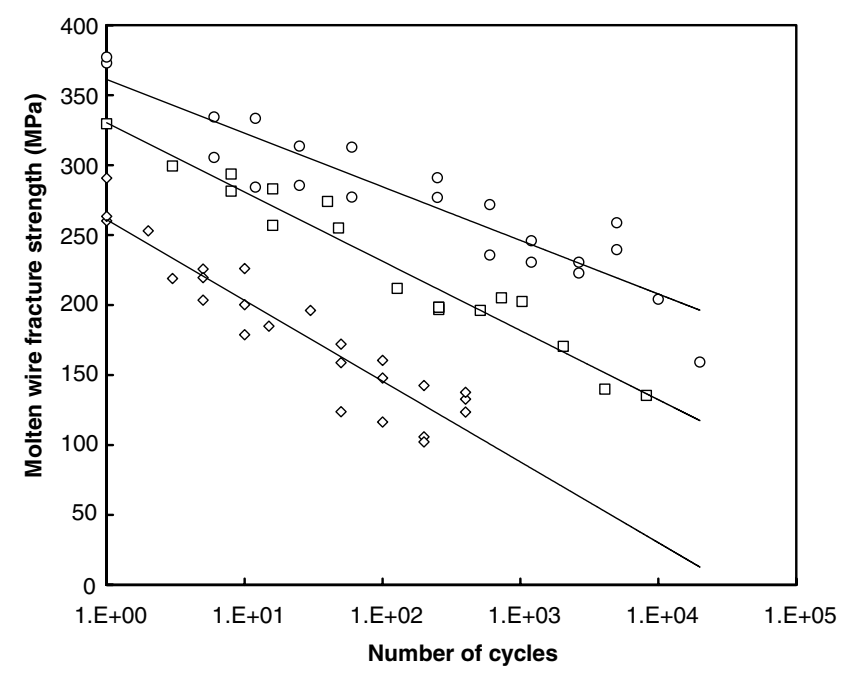

Fig. 1. Fracture stress of the molten wire as a function of the number of fatigue cycles experienced, for three peak stress values, namely $1100 \mathrm{MPa}$ (circles), $1160 \mathrm{MPa}$ (squares) and $1220 \mathrm{MPa}$ (diamonds). 


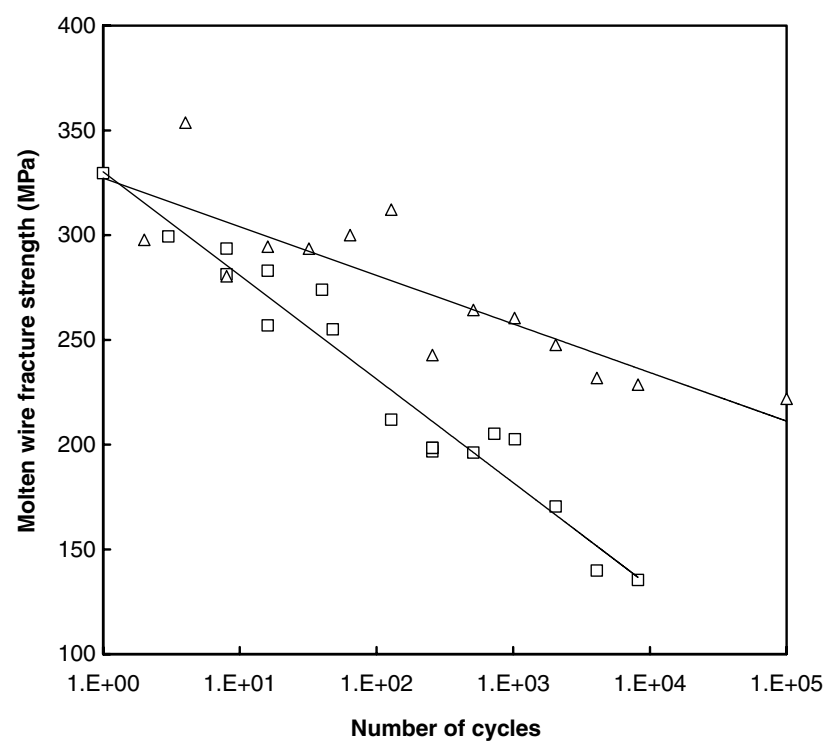

Fig. 2. Influence of stress-ratio, $R$, on the residual fracture stress of the molten wire for a maximum stress of $1160 \mathrm{MPa}: R=0.1$ (squares) and $R=0.9$ (triangles).

molten wire for a fixed maximum applied stress, $\sigma_{\max }$, of $1160 \mathrm{MPa}$. As $R$ increases from 0.1 to 0.9 , the fibres still experience damage; however, the rate of damage accumulation is lower for the higher $R$-value.

Some of the cycled wires were tested in a standard room temperature tension test after being cycled for various numbers of fatigue cycles. No strength decrease could be detected compared to virgin wires.

\section{Discussion}

Fatigue lives of samples tested to failure, although not statistically representative, are nonetheless comparable with the data published by Zhang et al. for a nominally identical wire and similar loading conditions $(R=0.1)[18]$.

Data from molten wire tensile tests of pre-fatigued samples show that fibres break in the composite during cyclic loading. They do so gradually as cycling progresses resulting in an increasing number of fibre breaks per unit fibre length.

The fracture strength, $\sigma_{\text {molten}}$, of the composite wire containing a molten zone of length $l$ obeys (see Eq. (3) in Ref. [22])

$$
\sigma_{\text {molten }}=C \cdot\left(c_{1} \cdot\left(1-D_{1}\right)^{l / l_{0}}+c_{2} \cdot\left(1-D_{2}\right)^{l / l_{0}}\right),
$$

where $C$ is a constant, equal to the wire fracture stress at the solid/liquid interface for the limiting case where all fibres are intact, or for $l=0 \mathrm{~mm}$. Subscripts 1 and 2 denote the two different fibre populations that exist in the virgin wire (this is a result of processing; see Ref. [22] for details); $c_{1}=0.25$ and $c_{2}=0.75$ are their respective fractions. $D_{1}$ and $D_{2}$ are the damage parameters of the two fibre regions, defined as the probability that a given fibre is fractured within a length $l_{0}$ of the composite wire. This reference length is fixed hereafter to $l_{0}=1 \mathrm{~mm}$. In the present study all wires were tested with a molten length $l=230 \mathrm{~mm}$.

It was shown previously that there is a certain amount of initial damage present in the as-produced wire and that, if the wires are stressed in tension, the amount of damage $D_{i}$ increases [22,24]. This increase of damage was also shown to correspond with predictions of the measured Weibull strength distribution of the virgin Nextel $610^{\mathrm{TM}}$ fibre if one makes the (reasonable) assumption that further damage accumulates equally in the two initial fibre populations of the wire, i.e., that the ratio between $\left(1-D_{1}\right)$ and $\left(1-D_{2}\right)$ remains constant. This observation implies that, during monotonic composite loading, the fibres behave in the composite as if they were bare.

Maintaining in what follows the assumption that the ratio between $\left(1-D_{1}\right)$ and $\left(1-D_{2}\right)$ remains constant after fatigue of the wire, the survival probability $S$ of a fibre of length $l_{0}=1 \mathrm{~mm}$ can be calculated from Eq. (1) as

$S \equiv \frac{1-D_{i}^{\text {cycled }}}{1-D_{i}^{\text {virgin }}}=\left(\frac{\sigma_{\text {molten }}^{\text {cycled }}}{\sigma_{\text {molten }}^{\text {virgin }}}\right)^{l_{0} / l}$,

where $D_{i}^{\text {cycled }}$ with $i=1$ or 2 is the damage parameter for the fibres in the cycled composite, $l=230 \mathrm{~mm} . \sigma_{\text {molten }}^{\text {virgin }}$ and $\sigma_{\text {molten }}^{\text {cycle }}$ are the measured molten wire strength values before and after fatigue of the composite.

In Eq. (2), ratio $S$ is the fraction of previously intact fibres along $1 \mathrm{~mm}$ of the composite wire that survived prior cyclic loading of the composite; $(1-S)$ is therefore the probability for fracture of intact fibres $1 \mathrm{~mm}$ long caused by cyclic loading of the composite. This is plotted

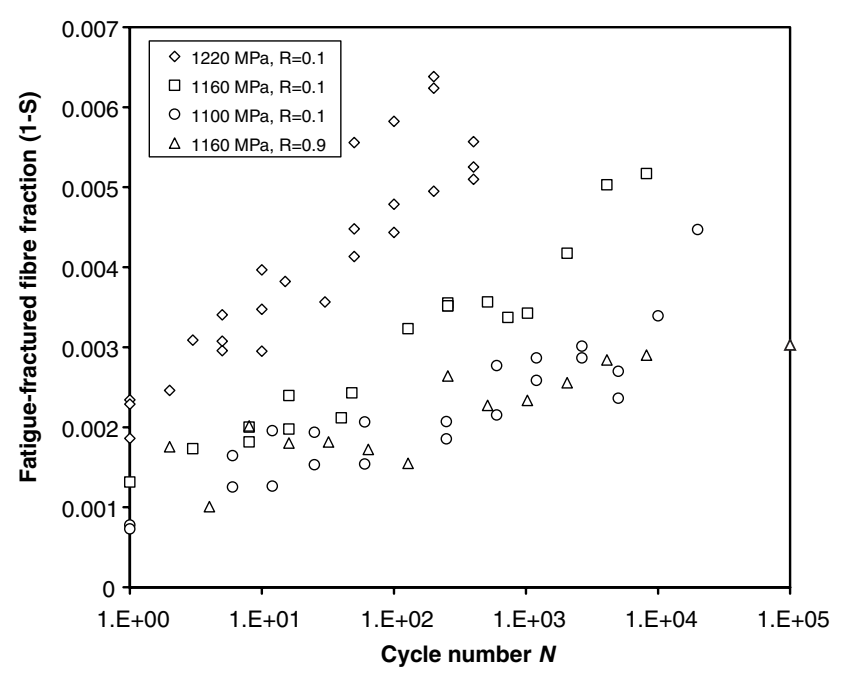

Fig. 3. Fraction of fatigue-fractured fibres $(1-S)$ in a length of $1 \mathrm{~mm}$, as a function of fatigue conditions (peak stress and $R$-ratio) and number of cycles, $N$. 
in Fig. 3, according to Eq. (2) from the data in Figs. 1 and 2 (for comparison, the shear stress transfer length at a broken fibre is below half a millimeter in this composite according to shear-lag theory). As seen, the number of fibre breaks remains relatively small but clearly increases with fatigue cycling. The trends found with increasing $\sigma_{\max }$ at fixed $R$, and with increasing $R$ at fixed $\sigma_{\max }$, are both as expected. The roughly linear increase in damage as a function of the logarithmic cycle number implies that fibre breaks accumulate rapidly during the first few cycles, after which the damage accumulation rate decreases gradually, as found in prior investigations of fatigue damage in heterogeneous materials $[25,26]$.

It is interesting to compare the amount of damage accumulated in fatigue with that resulting from monotonic straining. It was shown in Ref. [22] that damage introduced during monotonic loading agrees with predictions from Weibull statistics of the virgin fibre; in other terms:

$\frac{1-D_{i}^{\text {deformed }}}{1-D_{i}^{\text {virgin }}}=S_{\text {Weibull }}=\exp \left[-\frac{L}{L_{0}} \cdot\left(\frac{\sigma_{\mathrm{f}}}{\sigma_{0}}\right)^{\mathrm{m}}\right]$

where $D_{i}$ with $i=1$ or 2 , are the damage parameters normalized to $1 \mathrm{~mm}, L$ is $1 \mathrm{~mm}, L_{0}$ is the characteristic fibre length, $\sigma_{0}$ is the corresponding characteristic fibre strength, $\sigma_{\mathrm{f}}$ is the applied fibre stress and $m$ is the Weibull modulus. Values for virgin Nextel $610^{\mathrm{TM}}$ fibres are $m=11.2$ and $\sigma_{0}=3.47 \mathrm{GPa}$ with $L_{0}=25.4 \mathrm{~mm}$, from single fibre test data reported in the literature [15,21].

Working the numbers, it is found that, during fatigue cycling at $R=0.1$ with $\sigma_{\max }=1100 \mathrm{MPa}$, the amount of damage introduced after 1000 cycles is comparable to the damage introduced after 1 cycle with a peak stress of $1220 \mathrm{MPa}$ representing basically a monotonic loading. The increase in damage during cycling is thus significant. This suggests that the fibres themselves undergo fatigue damage, perhaps by subcritical growth of existing defects.

As noted above, if such a previously cycled composite is strained to failure at room temperature, the composite tensile strength is found to remain essentially unaffected. This suggests that damage introduced by cyclic loading nonetheless remains small, i.e. that the intact fibre segment length is long compared to the shear length and that fibre breaks are mainly uncorrelated.

The present data represent the statistical fracture probability of a large number of fibres after cyclic loading. Comparison of the present data with the individual fibre fatigue properties measured by Chawla et al. [19] requires that our statistical data be transformed into average fracture stresses for the cycled fibres. To this end, we make the assumption that, after fatigue loading, the Weibull statistics of the fibres maintain the same modulus $m$ (this approximation can be justified if the same fibre defect population causes fracture of the fibres in fatigue as in monotonic loading). The influence of fatigue damage on the fibre strength is then reflected in a reduced characteristic fibre strength $\sigma_{0}$.

The applied peak fibre stress during fatigue of the composite is estimated from the applied maximum composite stress $\sigma_{\max }$ and the fibre volume fraction $V_{\mathrm{f}}(=0.5$ in the present composite) as $\sigma_{\mathrm{f}}=\sigma_{\max } / V_{\mathrm{f}}$, thus neglecting the small load carried by the matrix. Matching $S$ in Eq. (3) for $\sigma_{\mathrm{f}}$ and $L=1 \mathrm{~mm}$, with the observed $S$ value derived from Eq. (2), the evolving characteristic fibre strength $\sigma_{0}$ can then be calculated as a function of the cycle number $N$. The average fracture stress (failure probability 0.5 ) of a fibre $L_{0}=20 \mathrm{~mm}$ long (the length tested by Chawla et al. [19]) cycled $N$ times to peak stress $\sigma_{\mathrm{f}}$ at the relevant value of $R$ is then deduced from Eq. (3). The result is shown in Fig. 4, where the thus estimated average strength of fibres cycled in the composite is compared with the single fibre $S-N$ data by Chawla et al. (note that their data were measured with $R=0.2$ ).

Fig. 4 shows clearly that all three curves with $R=0.1$ collapse indeed onto one single curve, as they should if the approximations made in the present estimation of the $S-N$ curve are correct. The stress ratio exerts an influence on the response, since the estimated $S-N$ curve lies somewhat higher for $R=0.9$; this of course reflects an $R$-ratio effect on the fibre fatigue strength. While our data suggest a considerably smaller slope for the $S-N$ curve compared to that plotted by Chawla et al., our results are fully within the range of their data, at least for $N \leqslant 10^{4}$.

This agreement between the two sets of data suggests in turn that damage accumulation by fibre breakage in the aluminium matrix composite proceeds during fatigue essentially as if the fibres were stressed analogously outside the composite, i.e., as bare fibres. This result parallels that found in Ref. [22] for monotonic tensile

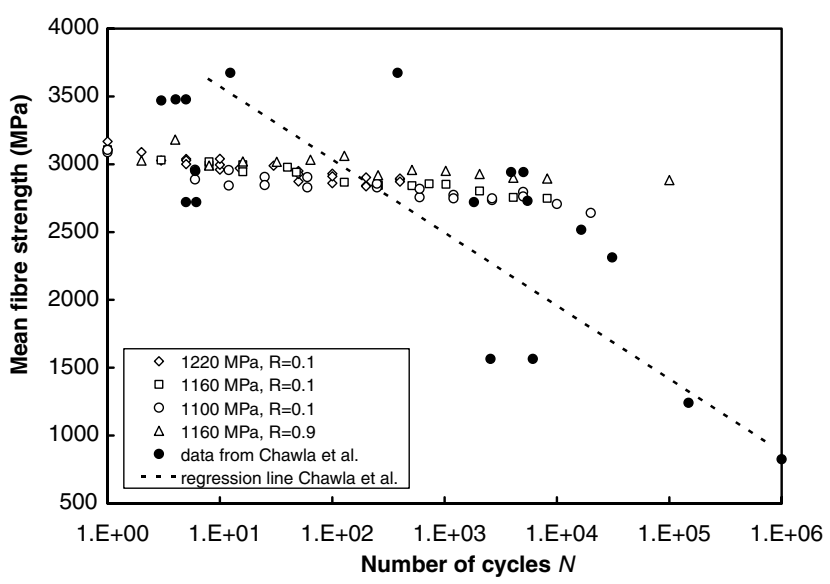

Fig. 4. Characteristic fibre strength as a function of cycle number. Calculated data from this study are compared with the published single fibre fatigue results by Chawla et al. [19]. 
loading. Although more data may be needed to confirm this conclusion, it implies that the fibre fracture process during fatigue of these composites is intrinsic to the fibres, rather than being a result of phenomena specific to the composite, such as stress concentrations induced by slip in the matrix.

\section{Conclusions}

- Fibre damage accumulation during cyclic loading in a continuous alumina fibre reinforced aluminium matrix wire can be measured using the molten matrix method described in Ref. [22].

- The number of fibre breaks during low-cycle fatigue in alumina fibre reinforced aluminium wires increases linearly with the logarithm of the cycle number.

- The damage accumulated and the rate of damage accumulation increase with increasing peak stress at constant stress ratio and with decreasing stress ratio at constant peak stress; this is as expected.

- Interpreting fatigue damage of the fibres in the composite as a reduction in their characteristic Weibull strength with a constant modulus $m$, it is found that the present data are consistent with data of Chawla et al. from isolated fibre fatigue testing [19].

- The results of this study show that, as in monotonic loading, fibres also fracture in fatigue within the composite as if they were identically stressed outside the composite.

\section{Acknowledgements}

This work was funded by a joint Empa/EPFL PhD thesis program, and by internal funding within Empa in Thun and the Laboratory for Mechanical Metallurgy at EPFL. The authors would like to thank the 3M Company for the donation of the composite wire used throughout this study and Dr. Colin McCullough of the $3 \mathrm{M}$ Company for many stimulating discussions on the general subject of this work.

\section{References}

[1] Zok FW. In: Kelly A, Zweben C, editors. Comprehensive Composite Materials, vol. 3. Oxford: Elsevier Science; 2000. p. 189-220.
[2] Chawla KK. In: Everett RK, Arsenault RJ, editors. Metal matrix composites: mechanisms and properties. London: Academic Press; 1991. p. 235-53.

[3] Xia ZH, Curtin WA. Acta Mater 2001;49:1633-46.

[4] Warrier SG, Majumdar BS. Metall Mater Trans A 1999;30: 277-86.

[5] Maruyama B, Warrier SG. Metall Mater Trans A 1999;30:267-75.

[6] Calcaterra JR, Mall S, Coghlan SC. Metall Mater Trans 1999; 30:307-13.

[7] Harmon D, Jerina KL. Metall Mater Trans 1999;30:255-66.

[8] Davenport SB, Gregson PJ, Moreton R, Peel CJ. J Mater Sci 1997;32:6555-60.

[9] Rao KTV, Siu SC, Ritchie RO. Metall Trans A 1993;24:721-34.

[10] Johnson WS. In: Andersen SI, Lilholt H, Pedersen OB, editors. Mechanical and physical behaviour of metallic and ceramic composites, Proceedings of the 9th Risø international symposium and metallurgy and materials science. Roskilde, Denmark, 1988. p. $403-11$.

[11] Gerold V. In: Andersen SI, Lilholt H, Pedersen OB, editors. Mechanical and physical behaviour of metallic and ceramic composites, Proceedings of the 9th Risø international symposium on metallurgy and materials science. Roskilde, Denmark, 1988, p. $35-50$.

[12] Page RA, Leverant GR. In: Harrigan Jr. WC, Strife J, Dhingra AK, editors. ICCM-V. San Diego, CA, USA, 1985, p. 867-86.

[13] Komai K, Minoshima K, Funato T. In: Masters JE, Gilbertson LN, editors. Fractography of modern engineering materials: composites and metals. ASTM STP 1203, vol. 2. West Conshohocken, PA: American Society for Testing and Materials ASTM; 1993. p. 145-70.

[14] Deve HE, McCullough C. J Minerals Metals Mater Soc 1995;47: 33-7.

[15] Wilson DM, Visser LR. Compos Part A 2001;32:1143-53.

[16] Jacquesson M, Vidal-Setif MH, Valle R, Godin N, Girard A, Fougeres R. Mater Sci Technol 2000;16:830-6.

[17] Zhang WL, Gu MY, Chen JY, Wu ZG, Zhang F. J Mater Sci Lett 2002;21:767-9.

[18] Zhang W, Gu M, Chen J, Wu Z, Zhang F, Deve HE. Mater Sci Eng 2003;A341:9-17.

[19] Chawla N, Kerr M, Chawla KK. J Am Ceram Soc 2005;88:101-8.

[20] Bunsell AR, Berger MH. J Eur Ceram Soc 2000;20:2249-60.

[21] Wilson DM, Visser LR. In: Ceramic engineering and science proceedings. 24th Annual conference on composites, advanced ceramics, materials, and structures: B, Jan. 23-28, 2000. Cocoa Beach, FL, USA, 2000, p. 363-73.

[22] Moser B, Rossoll A, Weber L, Beffort O, Mortensen A. Acta Mater 2004;52:573-81.

[23] Moser B. Deformation and fracture of continuous alumina fibre reinforced aluminium, Department of Materials Science, EPFL, 2002.

[24] Moser B, Rossoll A, Weber L, Beffort O, Mortensen A. J Microsc 2003;209:8-12.

[25] Mao H, Mahadevan S. Compos Struct 2002;58:405-10.

[26] Subramanian S, Reifsnider KL, Stinchcomb WW. Int J Fatigue 1995;17:343-51.

[27] 3M Company. Nextel ceramic textiles technical notebook. Available from: http://www.3m.com/ceramics/misc/tech_notebook. jhtml, 2002. 